\title{
Factors that influence healing of chronic venous leg ulcers: a retrospective cohort
}

\author{
Marilia Formentini Scotton ${ }^{1}$ \\ Luciana Patricia Fernandes Abbade ${ }^{1}$
}

Hélio Amante Miot ${ }^{1}$

\begin{abstract}
BACKGROUND: Venous ulcers have a significant impact on patient quality of life, and constitute a worldwide public health problem. Treatment is complex, with high failure rates.

OBJECTIVES: To identify clinical and therapeutic factors that influence healing of venous ulcers.

METHODS: Retrospective cohort study of patients with venous ulcers. Ulcer area was measured at the first visit (T0) and after 6 months (T6) and 1 year (T12). A reduction in ulcer area of 50\% or more at T6 and T12 was the outcome of interest, weighted by clinical, demographic and treatment aspects.

RESULTS: Ninety-four patients were included (137 ulcers). A reduction in ulcer area of $50 \%$ or more was seen in $40.1 \%$ of patients (95\% CI 31.9 to $48.4 \%$ ) at T6 and $49.6 \%$ (95\% CI 41.2 to $58.1 \%$ ) at T12. Complete healing occurred in $16.8 \%$ (95\% CI 10.5 to $23.1 \%$ ) at T6 and 27\% (95\% CI 19.5 to 39.5\%) at T12. The lowest ulcer area reductions at T6 were associated with longstanding ulcer ( $\mathrm{RR}=0.95 ; 95 \% \mathrm{CI} 0.91$ to 0.98 ), poor adherence to compression therapy ( $\mathrm{RR}=4.04 ; 95 \% \mathrm{CI} 1.31$ to 12.41 ), and infection episodes $(\mathrm{RR}=0.42 ; 95 \% \mathrm{CI} 0.23$ to 0.76 ). At T12, lower reductions were associated with longstanding ulcer ( $\mathrm{RR}=0.95 ; 95 \% \mathrm{CI} 0.92$ to 0.98$)$, longer topical antibiotic use ( $R R=0.93 ; 95 \% \mathrm{CI} 0.87$ to 0.99 ), and systemic antibiotic use ( $R R=0.63 ; 95 \% \mathrm{CI} 0.40$ to 0.99 ).

CONCLUSIONS: Longstanding ulcer, infection, poor adherence to compression therapy, and longer topical and systemic antibiotic use were independently correlated with worse healing rates.
\end{abstract}

Keywords: Cohort studies; Leg ulcer; Lower extremity; Risk factors; Varicose ulcer; Wound healing

\section{INTRODUCTION}

Chronic leg ulcers are defined as wounds located below the knee that do not heal within a 6-week period. $^{1,2}$ There are three main types of leg ulcers: venous, arterial, and neuropathic. Venous ulcers (VUs) account for approximately $75 \%$ of all chronic leg ulcers, and are characterized by several factors that hinder and delay healing.

VUs affect patients of both sexes, and are most common in older adults. They constitute a public health issue in Brazil and worldwide, being associated with absence from work, frequent physician visits, and high treatment-related expenses. ${ }^{1,3,4}$

The prevalence of VUs varies between studies, due to the heterogeneity in diagnostic methods and epidemiological characteristics of the sample and depending on whether foot ulcers are included as well. ${ }^{5,6}$ In Brazil, Maffei et al. (1986) ${ }^{7}$ found a 3.6\% prevalence of active and/or healed VUs in a sample of 1,755 individuals aged $>15$ years.
VUs develop in the context of advanced chronic venous insufficiency (CVI) with dysfunction of the calf muscle pump..$^{5,89}$ The venous hypertension caused by venous valve incompetence, which is common in primary varicose veins and post-thrombotic syndrome and may affect the superficial, communicating (perforator), or deep venous systems in isolation or concomitantly, is the key to ulcer development. Nevertheless, the exact mechanism whereby venous hypertension leads to VUs is unknown. Recent studies suggest that the pathogenesis of the ulceration process is associated with the abnormal changes in microcirculation and consequent inflammatory response inherent to $\mathrm{CVI}{ }^{10,11}$

Clinically, VUs are characterized by irregular shape, with a sharply demarcated border; a yellow exudate is often seen on the wound bed. Most are superficial, with potential for deep extension, although tendon exposure and necrosis are unusual. VUs may be single or multiple, and of varying size;

Received on 11.04.13.

Approved by the Advisory Board and accepted for publication on 17.06.2013.

* Work performed at the Department of Dermatology and Radiotherapy, Faculdade de Medicina de Botucatu - Universidade Estadual Paulista "Júlio de Mesquita Filho" (UNESP) - Botucatu (SP), Brazil

Financial support: none.

Conflict of interests: none.

Universidade Estadual Paulista "Júlio de Mesquita Filho" (UNESP) - Botucatu (SP), Brazil. 
they are usually slow to develop, but onset may be sudden. Location is also variable, although the distal region of the legs - particularly over the medial malleolus - is most commonly affected ${ }^{6}$

Management of VUs is complex, and ranges from clinical treatment to surgical therapy of the underlying venous abnormality. ${ }^{11}$ Compression therapy is a key element.

Knowledge of the factors that contribute to failure of VU healing is essential for prognostication and development of treatment strategies. Within this context, the present study seeks to identify clinical, demographic, and treatment-related factors that influence VU healing.

\section{MATERIALS AND METHODS}

This was a retrospective cohort study of patients with chronic venous leg ulcers treated at the outpatient ulcer clinic of the Department of Dermatology, da Faculdade de Medicina de Botucatu - UNESP, from 2000 to 2010. The study was approved by the local research ethics committee, and was carried out in accordance with the principles set forth in the Declaration of Helsinki.

Clinical, demographic, and treatment-related variables were assessed in all selected patients over a 1-year period from their first visit to the outpatient ulcer clinic.

The inclusion criteria were: diagnosis of chronic leg ulcers of venous etiology; at least 12 months' follow-up; and knowledge of ulcer area at the first visit (T0) and approximately 6 months (T6) and 12 months (T12) thereafter. The exclusion criteria were chronic leg ulcers of any other etiology and VUs associated with peripheral artery disease.

Chronic venous leg ulcers were defined as any VU located below the knee for over 6 weeks with one or more of the following manifestations: edema, hyperpigmentation (stasis dermatitis), eczema, lipodermatosclerosis, and varicose veins.

Peripheral arterial disease was defined by an ankle-brachial index (ABI), calculated using a $10-\mathrm{mHz}$ handheld vascular Doppler device (DV 610B), of $<0.9$ and/or absence of distal pulses.

Ulcers were considered post-thrombotic when the patient had a history of deep venous thrombosis (DVT) of the affected limb or when patient records contained a history of DVT. Ulcers were considered due to primary varicose veins when varicose disease was present but there was no history of DVT.

Each ulcer was initially demarcated by tracing its borders onto clear plastic film. Each tracing was then transferred onto a blank sheet of paper, and a sticker of known size was placed next to the tracing for scale. The tracing and sticker were then pho- tographed with a compact digital camera. Using the external scale reference (sticker), we established the pixel/cm relationship for each photo. Having established that relationship, we manually traced the perimeter of each ulcer in image editing software (Image J $1.46^{12}$ ) to calculate its area in pixels, which was then converted to $\mathrm{cm}^{2}$.

Information on the variables of interest was collected from patient records, into a form designed specifically for this purpose (Chart 1 ).

The sample size was defined on the basis of a pre-test of 60 ulcers using the Freeman formula $\left(n=10^{*}[k+1]\right)$, with attention to the covariates that indicated the composition of the final multivariate model and keeping a proportion of at least five events for each covariate with potential influence on the outcome of interest $(p<0.25)$. As the pre-test yielded nine covariates and estimated that $50 \%$ of ulcers would heal $(>50 \%$ reduction in area) during the period of interest, the final sample size was defined as 100 ulcers. ${ }^{13}$

Categorical variables were expressed as percentages, and bivariate comparisons performed using the chi-square or Fisher's exact tests. Quantitative variables were tested for normality with the ShapiroWilk test and expressed as means and standard deviations or medians and interquartile ranges (IQR = p25-p75) as appropriate. The Student $t$ or MannWhitney $U$ tests were used for bivariate comparisons as appropriate.

Longitudinal repeated measures of ulcer areas were assessed by a generalized linear mixed effects model (gamma probability distribution).

We then carried out a multivariate analysis with Poisson regression (log-linear model). Selection of variables for the final model was based on a hierarchical structure; as long as a given covariate had a pvalue $<0.25$ among all covariates within each hierarchical block, it was kept for analysis of the next block (Chart 2). Covariates in which a suppression effect was identified were kept in the model.

The variables of the final model were tested for interaction effect in $2 \times 2$.

For multivariate analysis, missing data were filled in by means of the multiple imputation method, as long as they represented less than $10 \%$ of the data for the subject or variable of interest.

Effect size was estimated as relative risk (RR) with respective 95\% confidence intervals (95\% CI).

Data were tabulated and analyzed in IBM SPSS 20 software. The significance level was set at $\mathrm{p}<0.05$.

\section{RESULTS}

A total of 168 patients whose first visit took place between 2000 and 2010 were selected. Of these, 
CHART 1: Data collection protocol for patients with venous ulcers

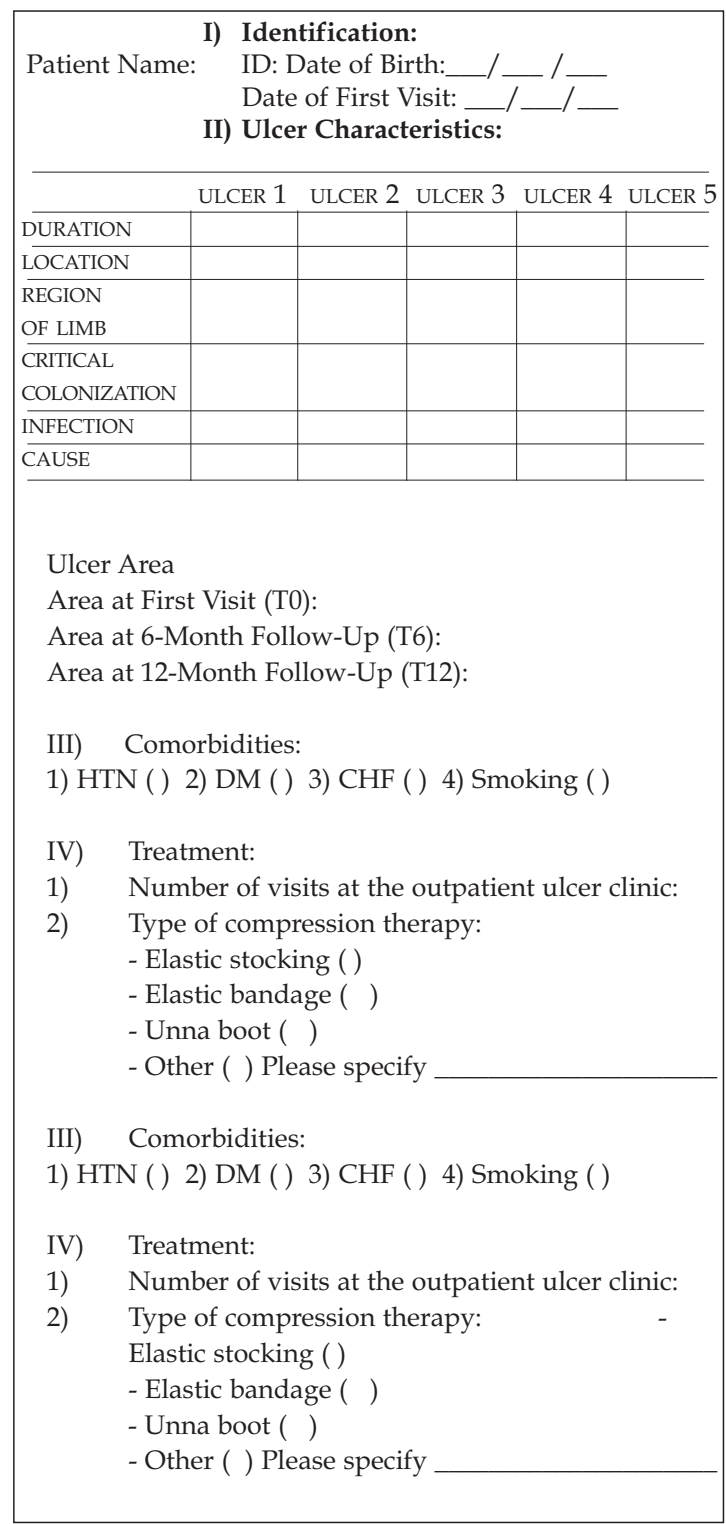

CHART 2: Hierarchical structure of study covariates for multivariate analysis. First level, patient-related/ulcer-related variables; second level, treatment-related variables

\section{First level: Patient-related / ulcer-related variables}

Sex, age, active ulcer duration, ulcer location and area; episodes of critical colonization or infection; post-thrombotic etiology, high blood pressure, diabetes mellitus.

Second level: Treatment-related variables

Compliance with rest, occlusive dressings, and compression therapy; duration of use of debriding dressings, topical antibiotics, and systemic antibiotic use.
$74(44.04 \%)$ were excluded for the following criteria: 17 ulcers for which 12-month follow-up was not available (22.97\%); eight ulcers of mixed etiology (10.81\%); four cases of neuropathic plantar ulceration (mal perforant) $(5.40 \%)$; seven ulcers on which no data could be collected for the protocol $(9.45 \%)$; seven ulcers of unknown etiology (9.45\%); four ulcers secondary to bullous erysipelas (5.40\%); and 27 ulcers due to other causes $(36.48 \%)$, namely: photodynamic therapy, polycythemia vera, peripheral artery disease, hypertension, burns, rheumatoid arthritis, basal cell carcinoma, spindle cell carcinoma, brown recluse spider bite, pyoderma gangrenosum, subungual verruca vulgaris, livedoid vasculopathy, and leprosy.

The overall profile of the 94 patients included is shown in table 1 . Noteworthy findings include advanced age, a substantial proportion of ulcers larger than $20 \mathrm{~cm}^{2}(43 \%)$ at baseline (T0), and the female majority of the sample, for a total of 137 ulcers. The duration of active ulceration ranged from 12 months to 39 years (Table 1 ).

Graph 1 shows the distribution of ulcer areas at $\mathrm{T} 0, \mathrm{~T} 6$, and $\mathrm{T} 12$. $\mathrm{A} \geq 50 \%$ reduction in area was observed in $40.1 \%$ of ulcers (95\% CI $31.9-48.4 \%$ ) at T6 and $49.6 \%$ of ulcers (95\% CI $41.2-58.1 \%$ ) at $\mathrm{T} 12$. Complete healing occurred in $16.8 \%$ of ulcers $(95 \% \mathrm{CI}$ $10.5-23.1 \%)$ at $\mathrm{T} 6$ and $27 \%$ (95\% CI $19.5-39.5 \%)$ at $\mathrm{T} 12$. Statistically significant reductions in area occurred between T0 and T12 and between T6 and T12 ( $<<0.01)$, but not between T0 and T6 $(\mathrm{p}=0.74)$.

Table 2 shows bivariate and multivariate analyses of the variables of interest with regard to reduction in VU area to $<50 \%$ of baseline at 6 -month follow-up (T6). These analyses revealed that duration of ulcer progression, episodes of infection, and poor compliance with compression therapy had a significant negative impact on healing.

Table 3 shows bivariate and multivariate analyses of the variables of interest with regard to reduction in VU area to $<50 \%$ of baseline after 12 months of treatment (T12). Duration of ulcer progression and use of topical and systemic antibiotics were found to have significant negative impacts on long-term healing.

The $2 \times 2$ interactions of the final model variables for T6 and T12 did not yield significant products $(p>0.05)$.

\section{DISCUSSION}

In this series of 94 patients with chronic venous leg ulcers, significant reductions in ulcer area were observed over a 12-month follow-up period, ratifying the need for persistence in the treatment of VUs.

Labropoulos et al. assessed the progression of 153 VUs in 127 patients in the New York region. ${ }^{14}$ The factors associated with nonhealing were advanced age, increased body mass index, history of DVT, non- 


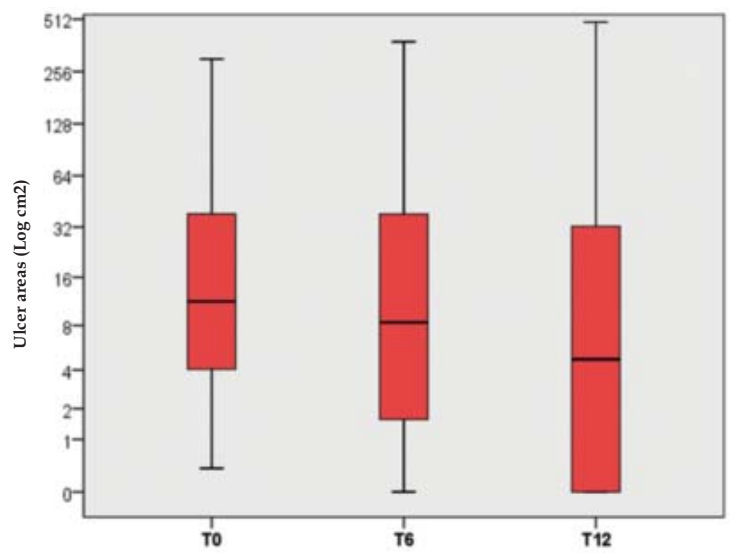

Observation times

Generalized linear mixed effects model (gamma regression) $\mathrm{p}<0.01$ T0xT6 p=0.74 T0xT12 and T6xT12 p=0.01 (Bonferroni)

GRAPH 1: Representation of ulcer areas (Log2 of $\mathrm{cm} 2)$ at T0, T6, and T12

compliance with compression therapy, and large ulcer area. In our study, duration of active ulcer, episodes of local infection, and use of antibiotics correlated with a poor prognosis for healing. These situations are very common and may reflect ineffective or inappropriate prior attempts at therapy.

In our sample, active ulcer duration was prolonged, more so than in other studies. ${ }^{15}$ This was probably due to the fact that our center is a referral service for chronic ulcer care and receives patients from many other health facilities, including a large number of cases of treatment failure.

An influence of ulcer chronicity on the healing process was also found by Margolis et al., in a U.S. study conducted in Pennsylvania in the 1990s. ${ }^{15}$ The authors suggest that, the longer the active ulcer time, the harder it is to achieve healing, as a wide range of time-dependent changes may occur in the ulcer microenvironment, such as: excessive amounts of matrix metalloproteinases, collagenases, and elastases, which cause an early breakdown of collagen and growth factors; phenotypic alteration of wound cells, particularly fibroblasts, which would hinder their capacity for proliferation and movement; and a hypoxic microenvironment conducive to a high rate of fibroblast proliferation, leading to tissue fibrosis, as well as a greater tendency toward bacterial and fungal colonization. ${ }^{16}$

Some studies have shown that colonization and infection play a role in delaying the healing of chronic ulcers ${ }^{16-18}$ In our sample, these factors were present in a substantial percentage of cases, demonstrating how often these conditions occur in patients with chronic leg ulcers. Episodes of critical colonization did not correlate with poor healing, but infection was a major factor associated with worse prognosis during follow-up.

The lack of association between critical colonization and poor prognosis in our patients may be justified by the fact that adequate therapy, such as surgical debridement and activated charcoal/silver or hydrofiber/silver dressings, was provided whenever this condition was diagnosed clinically. These measures probably enabled early treatment of critical colonization, thus attenuating its influence on the healing process.

The chronic wound microenvironment is complex and usually contaminated by more than one species of bacteria. There may be formation of biofilms - communities of micro-organisms embedded within an extracellular polysaccharide matrix, which makes them more resistant to host defenses, antiseptics, and topical or systemic antibiotics. ${ }^{19}$ In our sample, longer topical and systemic antibiotic therapy correlated with poor prognosis at 12-month follow-up, suggesting that antibiotics are ineffective in promoting long-term healing of VUs.

The clinical dimension of infection varies in direct relation to bacterial load and virulence and is inversely proportional to host defenses.$^{20}$ In our case series, infection had a negative impact on the healing process at 6month follow-up, with no influence from antibacterial treatment, which consisted of systemic antibiotic therapy, often combined with surgical debridement of infected tissue (particularly in cases of necrosis and a substantial amount of devitalized tissue).

In our study, compliance with compression therapy had a major favorable effect on healing at 6 months. Other risk factors reported in the literature as having a negative influence on healing of chronic venous leg ulcers, such as advanced age, ulcer area at baseline, and post-thrombotic etiology, were not identified as such in our sample.

Labropoulos et al. found a history of DVT in $60 \%$ of patients with nonhealing ulcers. ${ }^{14}$ In our study, $13 \%$ of ulcers were post-thrombotic; however, there was no significant difference between those with and those without a 50\% reduction in area at 6 and 12 months.

External compression is regarded as essential to the VU healing process. ${ }^{21}$ Approximately $70 \%$ of patients in our sample used compressive elastic bandages and $40 \%$ wore an Unna boot at some point during the follow-up period. Compliance with compression therapy had a favorable effect on the healing process, but only at 6-month follow-up. 
TABLE 1: Overall profile of the sample

\begin{tabular}{|c|c|c|}
\hline Variable & Value & \\
\hline & $\mathbf{N}$ & $\%$ \\
\hline Sex & & \\
\hline Female & 67 & 71.3 \\
\hline Male & 27 & 28.7 \\
\hline Age (years) - median (IQR) & 60.5 & $52.1-70.2$ \\
\hline Number of visits - mean (SD) & 5.9 & 2.0 \\
\hline Duration of open ulcer (years) - median (IQR) & 4.0 & $2.6-8.1$ \\
\hline Ulcer area at baseline $(\mathrm{cm} 2)$ - median (IQR) & 11.4 & $4.0-38.4$ \\
\hline Number of ulcers per patient & & \\
\hline One & 58 & 61.7 \\
\hline Two & 29 & 30.9 \\
\hline More than two & 7 & 7.4 \\
\hline Affected leg & & \\
\hline Right & 62 & 45.3 \\
\hline Left & 75 & 54.8 \\
\hline Location on leg & & \\
\hline Medial & 48 & 35.6 \\
\hline Lateral & 34 & 25.2 \\
\hline Anterior & 24 & 17.8 \\
\hline Posterior & 9 & 6.7 \\
\hline More than one location & 20 & 14.8 \\
\hline Critical colonization during the first year of follow-up & 48 & 35 \\
\hline Infection during the first year of follow-up & 35 & 25.5 \\
\hline Etiology & & \\
\hline Primary varicose veins & 119 & 86.9 \\
\hline Post-thrombotic syndrome & 18 & 13.1 \\
\hline Comorbidities & & \\
\hline Hypertension & 66 & 48.2 \\
\hline Diabetes mellitus & 31 & 22.6 \\
\hline Heart failure & 1 & 2.7 \\
\hline Smoking & 14 & 14.3 \\
\hline Compression therapy & & \\
\hline Elastic stocking & 31 & 22.6 \\
\hline Elastic bandage & 99 & 72.3 \\
\hline Unna boot & 54 & 39.4 \\
\hline Type of dressing & & \\
\hline Debriding & 79 & 57.6 \\
\hline Topical antibiotic & 39 & 28.4 \\
\hline Occlusive (hydrogel, activated charcoal with silver, hydrocolloid, hydrofiber) & 82 & 59.8 \\
\hline Systemic antibiotic therapy & & \\
\hline Therapeutic & 36 & 26.3 \\
\hline Prophylactic & $6(4.4)$ & \\
\hline
\end{tabular}

$\mathrm{SD}$, standard deviation; IQR, interquartile range (p25-p75) 
TABLE 2: Bivariate and multivariate analysis of the outcome $>50 \%$ ulcer area reduction at $\mathrm{T} 6$

\begin{tabular}{|c|c|c|c|c|c|c|}
\hline \multirow[b]{2}{*}{ Variable } & \multirow[b]{2}{*}{$\begin{array}{l}>50 \% \text { area } \\
\text { reduction } \\
\text { at } \mathrm{T} 6(\mathrm{~N}=55)\end{array}$} & \multicolumn{2}{|c|}{ Bivariate analysis } & \multirow[b]{2}{*}{ p-value } & \multicolumn{2}{|c|}{ Multivariate analysis } \\
\hline & & $\begin{array}{l}\text { No }>50 \% \text { area } \\
\text { reduction } \\
\text { at } \mathrm{T} 6(\mathrm{~N}=82)\end{array}$ & $\begin{array}{l}\text { Relative risk } \\
(95 \% \mathrm{CI})\end{array}$ & & $\begin{array}{l}\text { Relative risk } \\
(95 \% \mathrm{CI})\end{array}$ & p-value \\
\hline Female sex ${ }^{a}$ & $34(62)$ & $62(76)$ & $0.70(0.47-1.06)$ & 0.09 & & \\
\hline $\begin{array}{l}\text { Patient age, } \\
\text { in years }\end{array}$ & $58(50-69)$ & $61(52-72)$ & $0.99(0.98-1.00)$ & 0.14 & & \\
\hline $\begin{array}{l}\text { Duration of } \\
\text { active ulcer, } \\
\text { in years }\end{array}$ & $3(2-7)$ & $5(2-17)$ & $0.97(0.93-1.00)$ & 0.09 & $0.95(0.91-0.98)$ & 0.01 \\
\hline Ulcer location ${ }^{\mathrm{a}}$ & & & & 0.55 & & \\
\hline Medial & $25(46)$ & $23(28)$ & $1.76(0.92-3.37)$ & & & \\
\hline Lateral & $12(22)$ & $22(27)$ & $1.43(0.69-2.98)$ & & & \\
\hline Anterior & $8(15)$ & $16(20)$ & $1.42(0.65-3.12)$ & & & \\
\hline $\begin{array}{l}\text { Other / } \\
\text { More than one }\end{array}$ & $10(18)$ & $21(26)$ & $1.00(-)$ & & & \\
\hline $\begin{array}{l}\text { Area at baseline, } \\
\text { in } \mathrm{cm}^{2}\end{array}$ & $7(4-25)$ & $20(4-87)$ & $1.00(0.99-1.00)$ & 0.21 & $1.00(0.99-1.00)$ & 0.16 \\
\hline $\begin{array}{l}\text { Critical } \\
\text { colonization }^{a}\end{array}$ & $15(27)$ & $33(40)$ & $0.69(0.42-1.15)$ & 0.15 & & \\
\hline Infection $^{\mathrm{a}}$ & $8(15)$ & $27(33)$ & $0.47(0.24-0.92)$ & 0.03 & $0.42(0.23-0.76)$ & 0.01 \\
\hline $\begin{array}{l}\text { Post-thrombotic } \\
\text { etiology }\end{array}$ & $9(16)$ & $9(11)$ & $1.10(0.61-1.97)$ & 0.76 & & \\
\hline Hypertension ${ }^{\mathrm{a}}$ & $24(44)$ & $42(51)$ & $0.80(0.52-1.23)$ & 0.32 & & \\
\hline Diabetes mellitus $^{\mathrm{a}}$ & $24(44)$ & $42(51)$ & $0.80(0.52-1.23)$ & 0.32 & & \\
\hline $\begin{array}{l}\text { Compliance } \\
\text { with rest }\end{array}$ & $39(71)$ & $49(60)$ & $1.21(0.76-1.91)$ & 0.42 & & \\
\hline $\begin{array}{l}\text { Compliance } \\
\text { with occlusive } \\
\text { dressings }^{\mathrm{a}}\end{array}$ & $46(84)$ & $76(93)$ & $0.68(0.42-1.09)$ & 0.11 & $1.18(0.42-3.30)$ & 0.75 \\
\hline $\begin{array}{l}\text { Compliance } \\
\text { with compression } \\
\text { therapy }\end{array}$ & $39(71)$ & $47(57)$ & $1.25(0.79-1.98)$ & 0.34 & $4.04(1.31-12.41)$ & 0.02 \\
\hline $\begin{array}{l}\text { Duration of } \\
\text { debriding dressing } \\
\text { use, in months }\end{array}$ & $1(0-4)$ & $2(0-9)$ & $0.97(0.92-1.01)$ & 0.13 & & \\
\hline $\begin{array}{l}\text { Duration of topical } \\
\text { antibiotic use, } \\
\text { in months }\end{array}$ & $0(0-0)$ & $0(0-2)$ & $1.02(0.97-1.07)$ & 0.49 & & \\
\hline $\begin{array}{l}\text { Therapeutic use } \\
\text { of systemic } \\
\text { antibiotics }\end{array}$ & $9(16)$ & $28(34)$ & $0.33(0.15-0.76)$ & 0.01 & & \\
\hline
\end{tabular}

${ }^{a}$ Qualitative variable expressed as N (\%); ${ }^{\text {b }}$ Quantitative variable expressed as median and interquartile range (IQR) 
TABLE 3: Bivariate and multivariate analysis of the outcome $>50 \%$ ulcer area reduction at $\mathrm{T} 12$

\begin{tabular}{|c|c|c|c|c|c|c|}
\hline \multirow[b]{2}{*}{ Variable } & \multirow[b]{2}{*}{$\begin{array}{l}>50 \% \text { area } \\
\text { reduction } \\
\text { at } \mathrm{T} 12(\mathrm{~N}=68)\end{array}$} & \multicolumn{2}{|l|}{ Bivariate analysis } & \multicolumn{3}{|c|}{ Multivariate analysis } \\
\hline & & $\begin{array}{l}\mathrm{No}>50 \% \text { area } \\
\text { reduction } \\
\text { at } \mathrm{T} 12(\mathrm{~N}=69)\end{array}$ & $\begin{array}{l}\text { Relative risk } \\
(95 \% \mathrm{CI})\end{array}$ & p-value & $\begin{array}{l}\text { Relative risk } \\
(95 \% \mathrm{CI})\end{array}$ & p-value \\
\hline Female sex ${ }^{a}$ & $47(69)$ & $49(71)$ & $0.96(0.67-1.38)$ & 0.83 & & \\
\hline $\begin{array}{l}\text { Patient age, } \\
\text { in years }\end{array}$ & $60(49-73)$ & $60(52-69)$ & $1.00(0.99-1.00)$ & 0.91 & & \\
\hline $\begin{array}{l}\text { Duration of } \\
\text { active ulcer, } \\
\text { in years }\end{array}$ & $3(1-6)$ & $6(3-18)$ & $0.95(0.92-0.99)$ & 0.01 & $0.95(0.92-0.98)$ & 0.02 \\
\hline Ulcer location $^{\mathrm{a}}$ & & & & 0.74 & & \\
\hline Medial & $25(37)$ & $27(33)$ & $1.28(0.75-2.19)$ & & & \\
\hline Lateral & $19(28)$ & $15(22)$ & $1.51(0.87-2.61)$ & & & \\
\hline Anterior & $11(16)$ & 13 (19) & $1.42(0.78-2.58)$ & & & \\
\hline $\begin{array}{l}\text { Other / More } \\
\text { than one }\end{array}$ & $13(19)$ & $18(26)$ & $1.00(-)$ & & & \\
\hline $\begin{array}{l}\text { Area at baseline, } \\
\text { in } \mathrm{cm}^{2}\end{array}$ & $10(4-38)$ & $13(5-82)$ & $0.99(0.99-1.00)$ & 0.18 & & \\
\hline $\begin{array}{l}\text { Critical } \\
\text { colonization }^{\mathrm{a}}\end{array}$ & $19(28)$ & $29(42)$ & $0.76(0.51-1.15)$ & 0.19 & & \\
\hline Infection $^{\mathrm{a}}$ & $14(21)$ & $21(30)$ & $0.63(0.38-1.04)$ & 0.07 & & \\
\hline $\begin{array}{l}\text { Post-thrombotic } \\
\text { etiology }\end{array}$ & $10(15)$ & $8(12)$ & $1.02(0.61-0.69)$ & 0.95 & & \\
\hline Hypertension ${ }^{a}$ & $29(43)$ & $37(54)$ & $0.82(0.58-1.17)$ & 0.28 & & \\
\hline Diabetes mellitus ${ }^{\mathrm{a}}$ & $12(18)$ & $19(28)$ & $0.81(0.51-1.28)$ & 0.36 & & \\
\hline $\begin{array}{l}\text { Compliance } \\
\text { with rest }^{\mathrm{a}}\end{array}$ & $45(66)$ & $43(62)$ & $1.08(0.75-1.56)$ & 0.68 & & \\
\hline $\begin{array}{l}\text { Compliance } \\
\text { with occlusive } \\
\text { dressings }^{\mathrm{a}}\end{array}$ & $61(90)$ & $61(88)$ & $1.15(0.65-2.03)$ & 0.64 & & \\
\hline $\begin{array}{l}\text { Compliance } \\
\text { with compression } \\
\text { therapy }\end{array}$ & $43(63)$ & $43(62)$ & $0.97(0.68-1.39)$ & 0.88 & & \\
\hline $\begin{array}{l}\text { Duration } \\
\text { of debriding } \\
\text { dressing use, } \\
\text { in months }\end{array}$ & $1(0-4)$ & $2(0-9)$ & $0.97(0.92-1.01)$ & 0.13 & & \\
\hline $\begin{array}{l}\text { Duration of } \\
\text { topical antibiotic } \\
\text { use, in months }\end{array}$ & $0(0-0)$ & $0(0-3)$ & $0.95(0.89-1.02)$ & 0.15 & $0.93(0.87-0.99)$ & 0.05 \\
\hline $\begin{array}{l}\text { Therapeutic } \\
\text { use of systemic } \\
\text { antibiotics }\end{array}$ & $14(21)$ & $23(33)$ & $0.66(0.40-1.09)$ & 0.10 & $0.63(0.40-0.99)$ & 0.05 \\
\hline
\end{tabular}

${ }^{\mathrm{a}}$ Qualitative variable expressed as N (\%); ${ }^{\mathrm{b}}$ Quantitative variable expressed as median and interquartile range (IQR) 
There is a consensus in the literature that the most effective intervention for treatment of VUs is strong compression, as it minimizes the effects of venous hypertension on the affected leg.,911,20,22-26 Compression acts on the macrocirculation by increasing deep venous return, reducing pathological reflux during walking, and increasing the stroke volume during activation of the calf muscles. Limb compression increases tissue pressure, thus facilitating resorption of edema and improving lymphatic drainage. Furthermore, it acts on the microcirculation to decrease fluid and macromolecule outflow from the capillaries and venules to the interstitial space, and can also stimulate fibrinolytic activity. ${ }^{9,21,27,28}$

Compression therapy plays an essential role in promoting healing and prolonging the recurrence-free period after complete healing. ${ }^{29}$ It may consist of a multi-layer dressing, elastic stocking, elastic bandage, or Unna boot. ${ }^{26}$ The current evidence is not sufficient to establish which provides greater benefit; instead, the adequate use of any of these methods is recommended.$^{24}$ Multi-layer compression wraps are currently considered the gold standard for treatment of leg VUs. However, this modality of compression therapy is still relatively unaffordable, particularly in the Brazilian Unified Health System, which was the setting of our study. ${ }^{25}$

Although diabetes mellitus may hinder healing of acute and chronic ulcerations, as poor glycemic control can have a negative impact on cytokine and growth factor release and on collagen synthesis, diabetes was not associated with poor prognosis in our sample; this finding is consistent with other studies. ${ }^{15,30,31}$ Like Margolis et al., we also failed to find any association between high blood pressure and treatment failure. ${ }^{15}$

While local ulcer care plays an important role in wound bed preparation to optimize healing, in our study, compliance with prescribed dressing care did not have an impact on the healing process. Overall, $88.6 \%$ of patients complied with prescribed dressings, but there were no statistically significant differences between those who did and those who did not. This finding is consistent with a systematic review of dressings for VUs, which showed that the type of dressing used in addition to compression therapy did not affect healing. ${ }^{25}$

\section{CONCLUSIONS}

Longer active ulcer duration, episodes of infection, poor compliance with compression therapy, and longer duration of topical and systemic antibiotic use were independently correlated with poor prognosis for ulcer healing. Other factors did not interfere significantly with healing, including age, ulcer area at baseline, diabetes mellitus, hypertension, post-thrombotic etiology, and compliance with dressings. On the basis of these findings, some measures may be planned to identify and prevent factors associated with poor healing prognosis. 


\section{REFERENCES}

1. Bergqvist $\mathrm{D}$, Lindholm $\mathrm{C}$, Nelzén 0 . Chronic leg ulcers: the impact of venous disease. J Vasc Surg. 1999;29:752-5.

2. Lin P, Phillips T. Ulcers. In: Bolognia JL, Jorizzo JL, Rapini RP, editors. Dermatology. New York: Mosby; 2003. p.1631-49.

3. Evans CJ, Fowkes FG, Ruckley CV, Lee AJ. Prevalence of varicose veins and chronic venous insufficiency in men and women in the general population: Edinburgh Vein Study. J Epidemiol Community Health. 1999;53:149-53.

4. Castro e Silva M. Chronic venous insufficiency of the lower limbs and its socio-economic significance. Int Angiol 1991; 10:152-7.

5. Fowkes FG, Evans CJ, Lee AJ. Prevalence and risk factors of chronic venous insufficiency. Angiology. 2001;52:S5-15.

6. Valencia IC, Falabella A, Kirsner RS, Eaglstein WH. Chronic venous insufficiency and venous leg ulceration. J Am Acad Dermatol. 2001;44:401-21.

7. Maffei FH, Magaldi C, Pinho SZ, Lastoria S, Pinho W, Yoshida WB, et al. Varicose veins and chronic venous insufficiency in Brazil: prevalence among 1755 inhabitants of a country town. Int J Epidemiol. 1986;15:210-7.

8. Gross EA, Wood CR, Lazarus GS, Margolis DJ. Venous leg ulcers: an analysis of underlying venous disease. Br J Dermatol. 1993;129:270-4

9. Zimmet SE. Venous leg ulcers: modern evaluation and management. Dermatol Surg. 1999;25:236-41.

10. Becker F. Mechanisms, epidemiology and clinical evaluation of venous insufficiency of the lower limbs. Rev Prat. 1994;44:726-31.

11. Abbade LPF, Lastória S. Afeccões ulcerosas. In: Belda Junior W, Di Chiacchio N Criado PR, eds. Tratado de Dermatologia. São Paulo: Atheneu; 2010. p. 2167 -97.

12. Miot HA, Mendacolli TJ, Costa SV, Haddad GR, Abbade LPF. Úlceras Crônicas dos Membros Inferiores: Avaliação pela Fotografia Digital. Rev Ass Med Bras. 2009:55:145-8.

13. Miot HA. Tamanho da amostra em estudos clínicos e experimentais. J Vasc Bras. 2011;10: $275-8$

14. Labropoulos N, Wang ED, Lanier ST, Khan SU. Factors associated with poor healing and recurrence of venous ulceration. Plast Reconstr Surg. 2012;129:179-86.

15. Margolis DJ, Berlin JA, Strom BL. Risk factors associated with the failure of a venous leg ulcer to heal. Arch Dermatol. 1999;135:920-6.
16. Falanga V. The chronic wound: impaired healing and solutions in the context of wound bed preparation. Blood Cells Mol Dis. 2004;32:88-94.

17. Mertz PM, Eaglstein WH. The effect of a semiocclusive dressing on the microbial population in superficial wounds. Arch Surg. 1984;119:287-9.

18. Dagher FJ, Alongi SV, Smith A. Bacterial studies of leg ulcers. Angiology. 1978:29:641-53

19. O'Meara S, Al-Kurdi D, Ologun Y, Ovington LG. Antibiotics and antiseptics for venous leg ulcers. Cochrane Database Syst Rev. 2010;20;:CD003557.

20. Dow G, Browne A, Sibbald RG. Infection in chronic wounds: controversies in diagnosis and treatment. Ostomy Wound Manage. 1999;45:23-7,29-40.

21. Partsch $H$. Compression therapy of the legs. A review. J Dermatol Surg Oncol. 1991;17:799-805

22. Smith PC, Sarin S, Hasty J, Scurr JH. Sequential gradient pneumatic compression enhances venous ulcer healing: a randomized trial. Surgery. 1990;108:871-5.

23. Bevis P, Earnshaw J. Venous ulcer review. Clin Cosmet Investig Dermatol. 2011;4:7-14.

24. Fletcher $A$, Cullum N, Sheldon TA. A systematic review of compression treatment for venous leg ulcers. BMJ. 1997;315:576-80.

25. Palfreyman S, Nelson EA, Michaels JA. Dressings for venous leg ulcers: systematic review and meta-analysis. BMJ. 2007:335:244.

26. Kahle B, Hermanns HJ, Gallenkemper G. Evidence-based treatment of chronic leg ulcers. Dtsch Arztebl Int. 2011;108:231-7.

27. Partsch B, Partsch H. Compression stockings for treating venous leg ulcers: measurement of interface pressure under a new ulcer kit. Phlebology. 2008;23:40-6.

28. O'Meara S, Cullum NA, Nelson EA. Compression for venous leg ulcers. Cochrane Database Syst Rev. 2009:CD000265.

29. Abbade LPF, Lastoria S. Abordagem de pacientes com ulcera da perna de etiologia venosa. An Bras Dermatol 2006;81:509-22.

30. Abbade LP, Lastória S, Rollo Hde A. Venous ulcer: clinical characteristics and risk factors. Int J Dermatol. 2011;50:405-11

31. Brand FN, Dannenberg AL, Abbott RD, Kannel WB. The epidemiology of varicose veins: the Framingham Study. Am J Prev Med. 1988;4:96-101.

How to cite this article: Scotton MF, Miot HA, Abbade LPF. Factors that influence healing of chronic venous leg ulcers: a retrospective cohort. An Bras Dermatol. 2014;89(3):414-22 